\title{
Review Article \\ Molecular Chaperone Dysfunction in Neurodegenerative Diseases and Effects of Curcumin
}

\author{
Panchanan Maiti, ${ }^{1}$ Jayeeta Manna, ${ }^{2}$ Shobi Veleri, ${ }^{3}$ and Sally Frautschy ${ }^{4,5}$ \\ ${ }^{1}$ Department of Neurology, University of Tennessee Health Science Center, Memphis, TN 38163, USA \\ ${ }^{2}$ Department of Physiology, University of Tennessee Health Science Center, Memphis, TN 38163, USA \\ ${ }^{3}$ Neurobiology-Neurodegeneration and Repair Laboratory, National Eye Institute, National Institutes of Health, Bethesda, \\ MD 20892, USA \\ ${ }^{4}$ Veteran's Greater Los Angeles Healthcare System, Geriatric Research and Educational Core, Los Angeles, CA 90073, USA \\ ${ }^{5}$ Departments of Neurology and Medicine, University of California at Los Angeles, Los Angeles, CA 90095, USA
}

Correspondence should be addressed to Panchanan Maiti; panchananm@gmail.com and Sally Frautschy; frauthsch@ucle.edu

Received 6 June 2014; Accepted 23 August 2014; Published 19 October 2014

Academic Editor: Michael Chen

Copyright (C) 2014 Panchanan Maiti et al. This is an open access article distributed under the Creative Commons Attribution License, which permits unrestricted use, distribution, and reproduction in any medium, provided the original work is properly cited.

The intra- and extracellular accumulation of misfolded and aggregated amyloid proteins is a common feature in several neurodegenerative diseases, which is thought to play a major role in disease severity and progression. The principal machineries maintaining proteostasis are the ubiquitin proteasomal and lysosomal autophagy systems, where heat shock proteins play a crucial role. Many protein aggregates are degraded by the lysosomes, depending on aggregate size, peptide sequence, and degree of misfolding, while others are selectively tagged for removal by heat shock proteins and degraded by either the proteasome or phagosomes. These systems are compromised in different neurodegenerative diseases. Therefore, developing novel targets and classes of therapeutic drugs, which can reduce aggregates and maintain proteostasis in the brains of neurodegenerative models, is vital. Natural products that can modulate heat shock proteins/proteosomal pathway are considered promising for treating neurodegenerative diseases. Here we discuss the current knowledge on the role of HSPs in protein misfolding diseases and knowledge gained from animal models of Alzheimer's disease, tauopathies, and Huntington's diseases. Further, we discuss the emerging treatment regimens for these diseases using natural products, like curcumin, which can augment expression or function of heat shock proteins in the cell.

\section{Introduction}

Current knowledge in the field supports the idea that accumulation of misfolded or mutant proteins inside and or outside neurons is an early event contributing to neurodegenerative disorders $[1,2]$. Neuron dysfunction caused by abnormal protein aggregation represents a major and unresolved medical challenge. The clinical manifestations depend on the afflicted brain region and may involve disruption of daily activities including sensory and motor functions such as moving, speaking, swallowing, breathing, or cognitive dysfunction. In particular, misfolding and aggregation of proteins are thought to be a major cause of synaptic loss and neuronal death observed in different neurodegenerative diseases $[1,3]$. Removal of aggregates can occur via different cellular processes, which, depending on the milieu, may aggravate or attenuate the disease process associated with Alzheimer's, Parkinson's, Huntington's, prion diseases, frontotemporal dementia, and motor neuron disease. Most importantly, to prevent the toxicity associated with misfolded protein aggregates, early diagnosis is critical to facilitate treatment prior to significant loss of neurons and accumulation of misfolded proteins and the onset of clinical symptoms. The mechanisms involved to clear protein aggregates in the cell are several, including molecular chaperones, the ubiquitin proteasome system, and autophagy pathways $[4,5]$. Although 
TABLE 1: Common neurodegenerative diseases due to protein misfolding and aggregation. The diseases associated with genetic/risk factors, proteins involved, pathology/diagnostic features, brain areas affected, and clinical symptoms in patients are mentioned below.

\begin{tabular}{|c|c|c|c|c|c|c|}
\hline Diseases & Genes involved & Risk factors & $\begin{array}{l}\text { Proteins } \\
\text { involved }\end{array}$ & Pathology & $\begin{array}{l}\text { Affected brain } \\
\text { areas }\end{array}$ & Symptoms \\
\hline Alzheimer's & $\begin{array}{c}\text { APP and } \\
\text { presenilin } 1,2\end{array}$ & ApoE4 & $\mathrm{A} \beta$ and Tau & $\begin{array}{l}\text { A } \beta \text {-plaque and } \\
\text { Tau tangle }\end{array}$ & $\begin{array}{l}\text { Hippocampus and } \\
\text { frontal cortex }\end{array}$ & $\begin{array}{c}\text { Memory loss, personality } \\
\text { change, worried, and } \\
\text { depressed }\end{array}$ \\
\hline Parkinson's & $\begin{array}{l}\alpha \text {-Synuclein, } \\
\text { Parkin, UCHL-1, } \\
\text { and LRRK2 }\end{array}$ & Tau linkage & $\begin{array}{c}\alpha \text {-Synuclein and } \\
\text { tau }\end{array}$ & $\begin{array}{l}\text { Lewy body and } \\
\text { tangle }\end{array}$ & $\begin{array}{l}\text { Substantia nigra, } \\
\text { striatum, and PFC }\end{array}$ & $\begin{array}{l}\text { Impairment of } \\
\text { sensorimotor } \\
\text { coordination and } \\
\text { cognition } \\
\end{array}$ \\
\hline Huntington & Huntingtin (HTT) & $\begin{array}{c}\text { Number of CAG } \\
\text { repeats in HTT } \\
\text { allele }\end{array}$ & Huntingtin & $\begin{array}{l}\text { Inclusion bodies } \\
\text { in cytoplasm } \\
\text { and nucleus }\end{array}$ & Striatum & $\begin{array}{c}\text { Uncontrolled movements, } \\
\text { clumsiness, and balance } \\
\text { impairment }\end{array}$ \\
\hline Prion & PRNP & $\begin{array}{l}\text { Homozygosity at } \\
\text { prion codon } 129\end{array}$ & $\operatorname{PrP} \mathrm{P}^{\mathrm{Sc}}$ & Prion plaque & Whole CNS & $\begin{array}{c}\text { Memory loss, personality } \\
\text { change, and movement } \\
\text { disorder }\end{array}$ \\
\hline $\begin{array}{l}\text { Amyotrophic } \\
\text { lateral sclerosis }\end{array}$ & SOD & - & SOD1 & Bunina body & $\begin{array}{l}\text { Motor neuron of } \\
\text { CNS }\end{array}$ & $\begin{array}{c}\text { Disturbances of muscular } \\
\text { activity }\end{array}$ \\
\hline $\begin{array}{l}\text { Multiple } \\
\text { sclerosis }\end{array}$ & $\begin{array}{l}\text { HLA, IL2RA, and } \\
\text { IL7RA }\end{array}$ & $\begin{array}{l}\text { Kinesin KIF1B, } \\
\text { Vit D }\end{array}$ & - & $\begin{array}{l}\text { Demyelinating } \\
\text { lesion }\end{array}$ & $\begin{array}{c}\text { White matter of } \\
\text { the brain and } \\
\text { spinal cord }\end{array}$ & $\begin{array}{l}\text { Physical and cognitive } \\
\text { disability }\end{array}$ \\
\hline Tauopathies & Tau & Tau-linkage & Tau & Tau tangle & Whole CNS & Memory loss \\
\hline $\begin{array}{l}\text { Lewy bodies } \\
\text { dementia }\end{array}$ & PARK11 & E4 allele of ApoE & $\begin{array}{c}\alpha \text {-Synuclein and } \\
\text { ubiquitin }\end{array}$ & Lewy bodies & $\begin{array}{l}\text { Hippocampus, } \\
\text { amygdale, and } \\
\text { frontal cortex }\end{array}$ & $\begin{array}{l}\text { Impair alertness/attention } \\
\text { movement, posture, } \\
\text { muscle stiffness, memory } \\
\text { loss, hallucinations, and } \\
\text { confusion }\end{array}$ \\
\hline
\end{tabular}

a moderate degree of autophagy has been shown to play a role in life extension, overstimulation of autophagy including macroautophagy can lead to cell death [6]. Therefore, molecular chaperone-mediated autophagy is thought to be the most specific and promising therapeutic approach to remove protein aggregates in the cells for neurodegenerative diseases $[4,5,7,8]$. Therefore, not surprisingly, there has been an escalation in research on role of molecular chaperones in degradation of misfolded protein debris in different neurodegenerative diseases $[2,9]$.

Molecular chaperones, such as heat shock proteins (HSPs), are part of a highly conserved cellular defense system, which regulates various cellular functions $[10,11]$. They provide protection against deleterious cellular stress by interaction with different cochaperones and other partnerproteins or by inducing expression of kinases, hormone receptors, transcription factors, or antioncogenic proteins [11, 12]. The principal roles of HSPs are to fold nascent polypeptides to their appropriate conformation, refold mild denatured/damaged proteins, prevent protein aggregation, and degrade severely damaged proteins and apoptosis [13-17]. The HSPs help to degrade the proteins by delivering them to the ubiquitin proteasome system [10]. They cannot complete these complex tasks alone, rather they require cochaperones and many other client-proteins such as kinases [18]. Although most of the cellular proteins can fold independently, HSPs are essential to efficiently facilitate the protein folding process [19]. Therefore, failure of these essential cellular quality control mechanisms leads to pathogenic conditions, as seen in different neurodegenerative diseases [20].

\section{Protein Misfolding and Aggregation Cause Neuronal Dysfunction}

Gradual accumulation of denatured or misfolded proteins over time leads to progressive loss of structure and/or function of neurons and ultimately neuronal death $[3,21]$. In most cases, the abnormal proteins are eventually deposited as insoluble intracellular or extracellular aggregates as amyloid plaques or intracellularly, for example, in neurofibrillary tangles, conditions known as amyloidosis, a process associated with neurodegeneration [3] (Table 1). The aggregation of misfolded proteins is highly regulated by both genetic and environmental factors [22].

Interestingly, most of the amyloid proteins (e.g., amyloid$\beta$, tau, $\alpha$-synuclein, huntingtin, prion, etc.) are metastable and noncrystalline in nature and have similar native structures $[23,24]$. Normally when proteins undergo conformational change in specific conditions and become denatured or misfolded, they are refolded in endoplasmic reticulum (ER) or degraded in the lysosome, but failure of this system leads to accumulation of insoluble amyloid aggregates (Figure 1). The current thought is that soluble, prefibrillar protein aggregates, particularly dodecamers (or larger oligomers) with specific conformations, are more neurotoxic than deposited amyloid fibrils [25]. Direct therapeutic targeting of aggregates is 


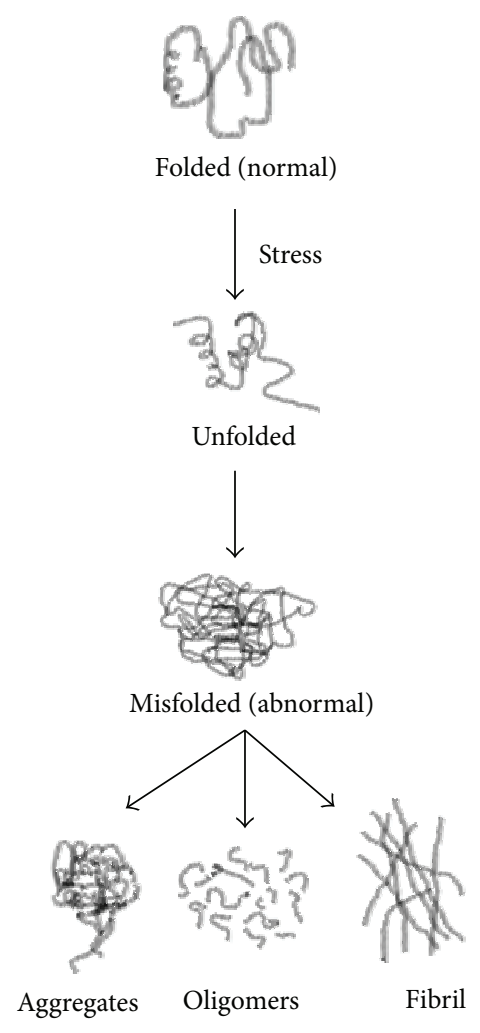

(a)

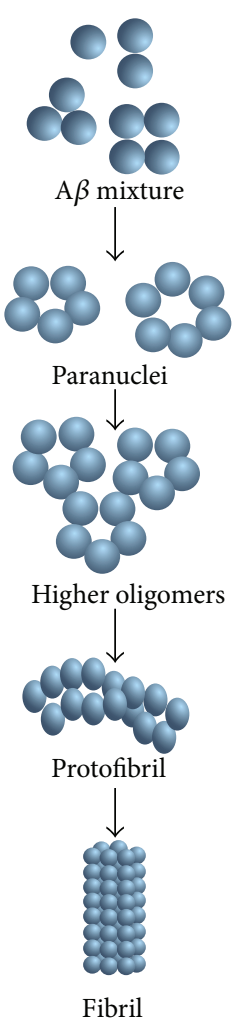

(b)

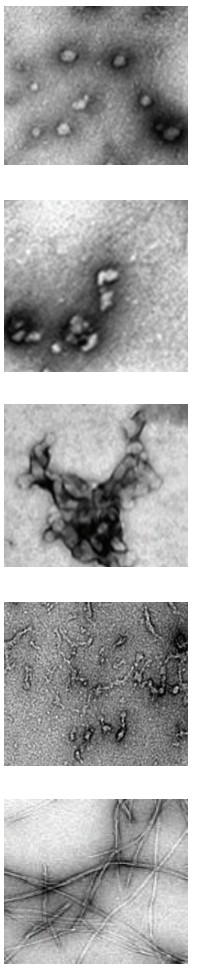

(c)


(d)


(e)

FIGURE 1: Protein misfolding and aggregation in different neurodegenerative diseases. (a) Schematic diagram showing steps of formation of different abnormal protein species after the cellular stress response; (b) schematic diagram of sequential formation of different amyloid species; (c) electron micrographs of different species of amyloid beta protein; (d) amyloid beta plaques (upper) stained with 4G8 antibody from brain tissue of AD mouse model, neurofibrillary tangle (middle), and synaptic (dendritic spine, Golgi-Cox stain) loss in mouse model of Alzheimer's disease (lower); (e) tyrosine hydroxylase (the indicator of dopaminergic neuron) positive (small arrow) neuronal loss in the substantia nigra pars compacta and tyrosine hydroxylase positive fibre loss in the striatum of MPTP-model of Parkinson's disease.

challenging because (1) the prefibrillar protein aggregates can have multiple structural conformations, (2) not all aggregates will be toxic, and (3) the different toxic species may be toxic through different mechanisms.

\section{Prevention of Neurodegeneration: Target Is Undefined}

Although the neurophysiological mechanisms of protein misfolding diseases are still not clear. Researchers are beginning to tackle the problems of aggregated proteins by applying a multifaceted approach to stop further neuronal death. Prior directions in drug development for AD have yielded disappointing results in trials, including strategies to (1) decrease the production of amyloidogenic proteins by inhibiting the rate-limiting enzyme responsible for production of the amyloidogenic protein (e.g., inhibition of $\beta$ and $\gamma$ secretases that produce $A \beta$ in $A D)$, (2) directly inhibit aggregation, and (3) promote phagocytic clearance of oligomers or amyloid by passive or active immunization or 4-inhibit enzymes that phosphorylate tau. Nevertheless it is untested whether combination therapies of these strategies will be effective. Further there is increased attention to increase neuroprotection by restoring endogenous pathways for maintaining protein homeostasis to enable effective protein degradation pathways and protein refolding, the cellular defense mechanisms against proteinopathies. There has recently been a focus on small molecules/drugs, bioactive phytochemicals, which can impact proteostasis and also exert neuroprotection through antioxidant and anti-inflammatory activity, particularly molecules classified by the Food and Drug Administration as generally recognized as safe (GRAS).

\section{Boosting the Cellular Defense System Can Protect against Proteinopathies}

Research efforts to boost the cellular defense system to treat neurodegenerative disease are underway. Unlike in disease, normally HSPs maintain protein quality control by several mechanisms including folding nascent protein, refolding and reactivation of unfolded and misfolded proteins, assembly and disassembly of macromolecular protein structures, and 
TABLE 2: Different heat shock proteins, their localization, functions, and involvement in different neurodegenerative diseases.

\begin{tabular}{|c|c|c|c|c|c|}
\hline HSPs & MW (kDa) & Localization & Colocalization & Functions & Involved in diseases \\
\hline HSP10 & 10 & $\begin{array}{l}\text { Mitochondria, } \\
\text { cytosol, ER, and } \\
\text { nucleus }\end{array}$ & $\mathrm{A} \beta$ & Protein folding & $\begin{array}{l}\mathrm{AD}, \mathrm{MS} \text {, and } \\
\text { tauopathies }\end{array}$ \\
\hline HSP27 & $20-30$ & $\begin{array}{l}\text { Cytosol, ER, and } \\
\text { nucleus }\end{array}$ & $\begin{array}{c}\text { Tau, A } \beta, \text { HTT, and } \\
\alpha \text {-synuclein }\end{array}$ & Protein degradation & $\mathrm{AD}, \mathrm{HD}$, and $\mathrm{PD}$ \\
\hline HSP40 & 40 & Cytosol & $\begin{array}{c}\text { HTT and } \\
\alpha \text {-synuclein }\end{array}$ & Protein folding & $\mathrm{HD}$ and $\mathrm{PD}$ \\
\hline HSP60 & 60 & Mitochondria & $\mathrm{A} \beta$ & $\begin{array}{l}\text { Prevent protein } \\
\text { aggregation }\end{array}$ & $\mathrm{AD}$ \\
\hline HSP70 & 70 & $\begin{array}{l}\text { Cytosol, ER, nucleus, } \\
\text { and mitochondria }\end{array}$ & $\begin{array}{c}\mathrm{A} \beta, \mathrm{HTT}, \\
\alpha \text {-synuclein, and } \\
\operatorname{PrP}^{\mathrm{c}}\end{array}$ & $\begin{array}{c}\text { Protein } \\
\text { folding/unfolding }\end{array}$ & $\begin{array}{c}\mathrm{AD}, \mathrm{HD}, \mathrm{PD}, \text { Prion, } \\
\text { and } \mathrm{MS}\end{array}$ \\
\hline HSP90 & 90 & Cytosol and ER & $\begin{array}{c}\mathrm{A} \beta, \mathrm{HTT}, \\
\alpha \text {-synuclein, and } \\
\operatorname{PrP}^{\mathrm{c}}\end{array}$ & $\begin{array}{l}\text { Protein degradation and } \\
\text { transcription factor }\end{array}$ & $\mathrm{AD}, \mathrm{PD}$, and $\mathrm{HD}$ \\
\hline HSP104/110 & $100-110$ & Cytosol and ER & $\begin{array}{c}\alpha \text {-synuclein and } \\
\operatorname{PrP}^{c} \\
\end{array}$ & Thermal tolerance & $\mathrm{PD}$ and prion \\
\hline
\end{tabular}

targeting abnormal and inactive proteins for degradation $[5,26,27]$. Different HSPs can be transported to synapses and axons and prevent aggregation of misfolded proteins. Recent experimental evidence suggests that HSPs have a significant role in direct inhibition of aggregation of those amyloidogenic proteins such as $\mathrm{A} \beta$, tau, HTT, and $\alpha$-synuclein and also promote ubiquitination and degradation of aggregated or misfolded proteins [28]. HSPs reduce the formation of annular, perhaps pore-forming species in favor of amorphous structures and fibrils as shown for the HTT fragment, suggesting prevention of channel formation [4]. In particular, the HSPs especially HSP40 and HSP70 regulate the disposal of toxic tau, $\mathrm{A} \beta, \alpha$-synuclein, and HTT aggregates via multiple mechanisms $[5,26,27]$. HSPs may bind in vitro and/or in vivo to prefibrillar mutant HTT [4], hyperphosphorylated tau, and $\alpha$-synuclein aggregates [3] to interfere with the formation of oligomer or higher order structures and to regulate the ubiquitin proteasome and the autophagic-lysosomal pathways [29]. Further, elevated levels of HSPs have been observed in activated astrocytes to target those proteins for degradation [8]. Besides protein refolding or degradation, HSPs also assist in a specialized autophagy mechanism called chaperonemediated autophagy (CMA). This is a highly selective and constitutive subtype of autophagy that utilizes chaperone proteins and lysosomal receptors to directly target proteins that contain a consensus pentapeptide motif, for example, KFERQ, and translocate them into the lysosomal lumen for their degradation [30]. In this case, the lysosome associated heat shock cognate 70 (Hsc70, a constitutively expressed chaperone) binds with target protein to form a substratechaperone complex and then is transported to the surface of endoplasmic reticulum where it can specifically bind with lysosomal receptor protein LAMP-2A. This is followed by unfolding, multimerization of LAMP-2A, and finally translocation of the target protein into lumen of ER for their final degradation. The interaction of LAMP-2A with Hsc70protein complex requires its stable structure and HSP90 to maintain this structure [31]. However, the failure of this important mechanism has been linked to the pathogenesis of several major neurodegenerative diseases [26, 32]. The crucial roles of HSPs in different neurodegenerative disease are discussed further.

\section{Characterization of Heat Shock Proteins and Their Functions}

In general, most eukaryotic cells constitutively express many chaperones and cochaperones, which are further modified by cellular stress. They are classified according to approximate molecular size or function into six conserved classes: HSP40, HSP60, HSP70, HSP90, HSP100, and the small HSPs (15 to $30 \mathrm{kDa}, \mathrm{HSP} 27, \mathrm{HSP} 10$ ) [33] (Table 2). They are localized in the nucleus, cytoplasm, and cellular organelles, such as mitochondria and ER [33]. Most importantly, HSPs are tightly regulated requiring a precise balance, while overproduction of certain HSPs can lead to diseases including cancer [12]. However, among all HSPs, low molecular weights (MW) HSPs are ATP-independent for their chaperone activity, whereas high MW HSPs are ATP-dependent $[13,16,17]$.

Small HSPs (sHSPs). The small HSPs are low MW chaperones ranging from $12-43 \mathrm{kDa}$ [34], localized in the cytosol as well as in different subcellular compartment including the ER and nucleus. Their expression varies with cellular environment and also in different neurological disorders. The most abundant and well understood sHSP is HSP27, while less is known about the less abundant sHSPs such as HSP10, HSP12, HSP20, and HSP26. Almost all these sHSPs share some common features including a small MW ranging from 12 to $43 \mathrm{kDa}$, a conserved $\alpha$-crystalline domain of $\sim 90$ residues, the ability to 


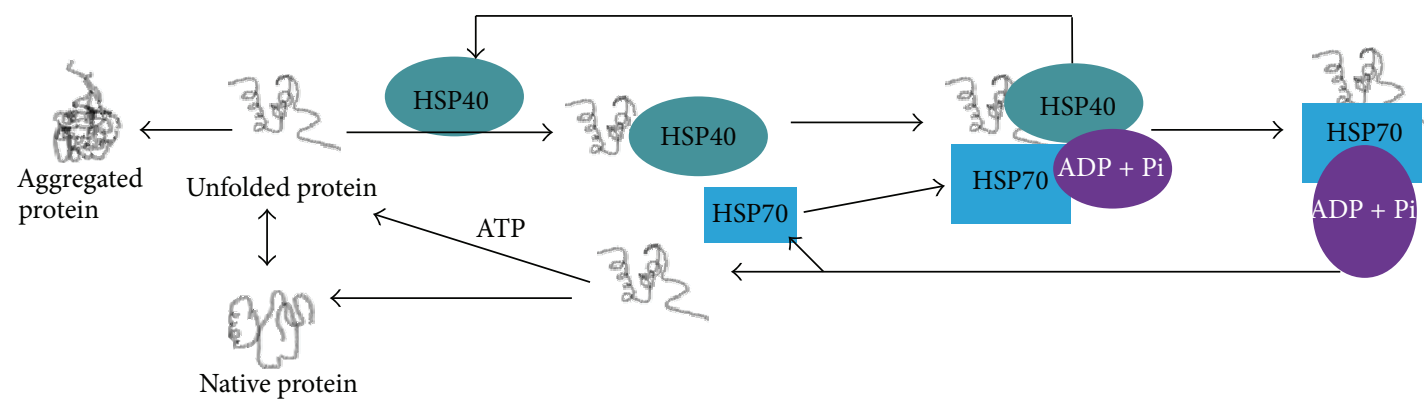

FIGURE 2: Role of HSP40 in protein folding and degradation. HSP40 acts as cochaperones of HSP70 and maintains ATPase activity required for proper function of HSP70.

form a large oligomers, and a dynamic quaternary structure. They have high chaperone activity that can attenuate protein aggregation, and increased expression is predominantly induced by cellular stress $[34,35]$. In addition to chaperone activity, the sHSPs are also involved in thermotolerance, cell development and differentiation, signal transduction, and inhibition of apoptotic cell death in vivo. They also serve as a cochaperone of HSP70 and assist inhibition of protein aggregation [34]. Other important functions of sHSPs are to assist in ubiquitin proteasome degradation of misfolded or denatured proteins. Further, they can increase glutathione to protect cells from oxidative damage. Finally, HSPs also have the ability to interact with actin and intermediate filaments and prevent their damage [35].

HSP40. HSP40 also known as chaperone DnaJ is a large protein family, which are the main cochaperones for HSP70 [36]. However HSP40 can also bind to aggregates and limit further aggregation or refold them without HSP70. There is little known about dysregulation of HSP40 in neurodegenerative disease; but it colocalizes with deposits and HSP40, and other HSPs correlate negatively with tau oligomers, an indicator of severity of disease [37]. Data using neurodegenerative cellular models of prion [38] or polyglutamine [39] aggregation argue a beneficial effect on limiting aggregation. It is expressed in a variety of organisms with different isoforms typically with three isoforms. All types of HSP40 contain a highly conserved J domain, which interact with HSP70 ATPase domain. Thus, HSP40 regulates ATPase activity of HSP70 (Figure 2). Further, it can carry substrate with an appropriate conformation to HSP70. Therefore, by stimulating the ATPase activity of HSP70, HSP40 is primarily associated with unfolded polypeptide chains and can reduce aggregates by protein translation, folding, unfolding, translocation, or degradation [40].

HSP60. HSP60 is a heptameric $60 \mathrm{kDa}$ mitochondrial chaperone. HSP60 works together with HSP70 for protein folding. Furthermore, it plays key roles in mitochondrial protein transport, replication, and transmission of mitochondrial DNA and apoptosis. For actin and tubulin, HSP60 is a specific chaperone. The main function of HSP60 is to assist protein folding and maintain the structural conformation [41, 42]. In addition, HSP60 transports and maintains mitochondrial proteins required for its DNA replication. Finally, cytoplasmic HSP60 interacts with antiapoptotic proteins to prevent cell death [43]. Depending on the demand and cellular milieu, HSP60 moves to and from the cytosol and mitochondria [4143].

HSP70. The most conserved chaperone in all living organisms is HSP70 (MW $70 \mathrm{kDa}$ ), which is localized in cytosol and also in organelles such as the endoplasmic reticulum (ER). HSP70, which makes complexes with unfolded or partially denatured proteins, has two functional domains: the ATPase domain and the substrate-binding domain (SBD). The activities of these domains are controlled by the availability of cellular ATP level. The ATPase domain of HSP70 supplies the required energy for the protein folding and maturation. Similarly, HSP70 binding to misfolded peptides increases the ATP hydrolysis. Further, HSP70 can interact with HSP40 and HSP90 to perform the process of protein folding. There is abundant evidence supporting a neuroprotective role in protein misfolding diseases including all of neurodegenerative disorders [44-46].

HSP90. The most abundant molecular chaperone in the cell is HSP90, a $90 \mathrm{kDa} \mathrm{MW}$ dimeric protein. It is one of the main HSPs, playing an important role in protein misfolding that stabilizes and activates more than 200 HSP90-client proteins required for cell signaling and adaptive responses to stress [47-49]. It is mainly localized in the cytosol but sometimes in the ER and mitochondria. HSP90 is a dimeric protein, which has a highly conserved N-terminal domain and a C-terminal domain (Figure 3). In the human proteome, inducible (HSP90 $\alpha$ ) and constitutive (HSP90 $\beta$ ) forms of HSP90 have been identified. The HSP90 is one of the main cytosolic molecular chaperones, which is activated with HSP40 and HSP70 [4, 5, 8] (Figure 3(b)). The main function of HSP90 is that it can stabilize certain protein complexes and assist in protein degradation (Figure 3(b)). However, its overexpression has been observed in cancers [26, 49]. For HSP90 to acquire the full active molecular chaperone activity HSP90, it requires a series of functionally related cochaperones, client/partner proteins, and multimeric protein complexes, like HOP, CDC37, P23 and Aha1, immunophilins (FKBP51 and FKBP52), peptidyl-prolyl isomerases and cyclophilin CYP40, and so forth $[4,50]$ (Figure 3(a)). 


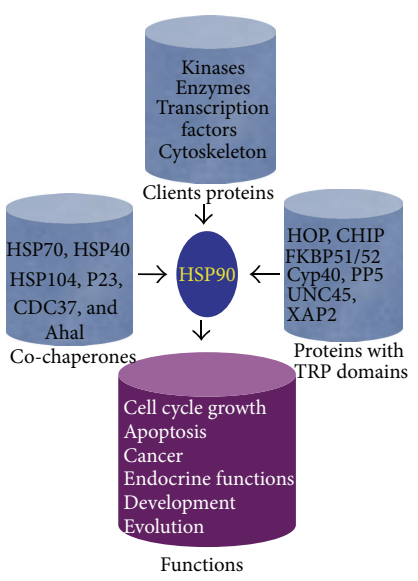

(a)

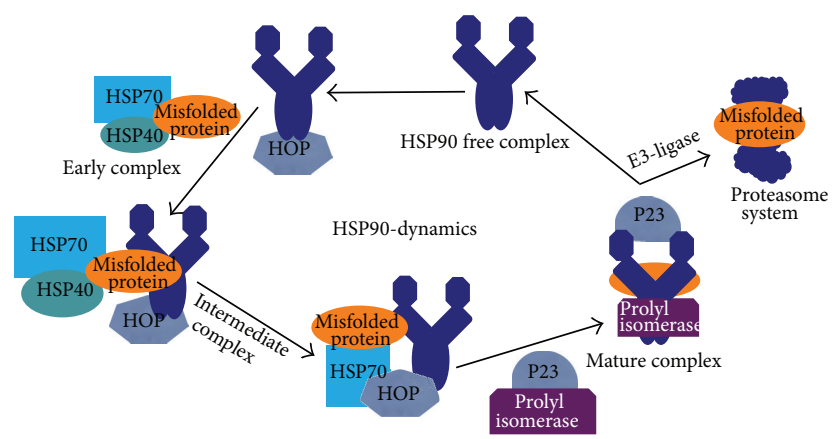

(b)

FIGURE 3: Schematic diagram of role of HSP90 and its cochaperones and client proteins in protein folding and degradation. (a) With the help of cochaperones, clients, and proteins with a TRP domain, HSP90 maintains protein quality control, cell cycle growth, development, and other essential activities of the cell. (b) Structural changes of HSP90 during protein folding and degradation. HSP90 dynamically changes from "open" to close structures. In its open form, it can bind with misfolded proteins along with other chaperones (early complex) and become a "closed" structure (mature complex). After releasing misfolded protein for proteasomal degradation, it goes to an "open" form (HSP90 free complex).

HSP100/104. The HSP100 is a hexameric cytosolic protein with great diversity of functions especially high thermotolerance [51]. Its $\mathrm{MW}$ ranges from 100 to $110 \mathrm{kDa}$, and originally discovered as $\mathrm{ClpA}, \mathrm{ClpB}$, and ClpC subfamilies [52]. In normal growth conditions the cells do not require HSP104/110, but its expression may be induced under extreme heat or exposure to other harsh environments to protect the cell and promote proteolytic degradation of specific cellular protein debris. In addition, sometimes HSP104/110 expression is required for regulation of transcription. Like HSP70, it has two main domains, the ATP binding region and the substrate-binding domain. HSP104/110 is a subclass of molecular chaperones that has the ability to solubilize almost any protein that becomes aggregated after severe stress [51] (Figure 4). Further, with the help of other chaperones such as HSP70 and HSP40, HSP100 breaks large protein aggregates into smaller aggregates and thus facilitates their proteasomal degradation [51]. Finally, HSP100 acts as a remodeling machinery, attempting to refold a misfolded protein or participate in the clearance of irreversible protein aggregates [51] (Figure 4).

\section{Role of HSPs in Different Neurodegenerative Diseases}

Alzheimer's Disease. The principal misfolded proteins in Alzheimer's disease (AD) are $\mathrm{A} \beta$ and tau [1]. The first one is formed from amyloid precursor protein (APP) and deposited as amyloid plaques, mostly in extracellular spaces. Tau is the microtubule stabilizing protein and when it is hyperphosphorylated accumulates intracellularly (and sometimes extracellularly) in neurofibrillary tangles [26, 32, 53, 54]. However, HSPs especially HSP70 can bind with APP and interfere with the APP secretory pathway to reduce the production of both $\mathrm{A} \beta 40$ and $\mathrm{A} \beta 42$ [55]. Dickey et al. reported that HSP70 and HSP90 interact with tau and A $\beta$ oligomers and degrade them through proteasome system [26] (Figure 5). Similarly, overexpression of HSP70 decreases the amount of insoluble tau, reduces tau phosphorylation, increases tau stability, promotes tau binding to microtubules, and decreases the in vitro and in vivo toxicity associated with tau protein [56] (Figure 5). In contrast, downregulation of HSPs by RNA-mediated interference (RNAi) has the opposite effect [5]. Heat shock cognate 70 (HSC70) together with HSP70 or HSP90 can directly bind to tau, independent of its phosphorylation status, thus facilitating microtubule polymerization and limiting tau aggregation [57]. In addition, HSP90 and its dependent cochaperones and client proteins may be essential for refolding denatured or misfolded tau and $\mathrm{A} \beta$ [57]. Both HSP70 and HSP90 can promote tau solubility and tau binding to microtubules as well as reduce insoluble tau and tau phosphorylation [5]. Overexpression of inducible HSP70 reduced soluble and insoluble tau levels in 30-month-old mice $[5,58]$. Levels of HSP90 are inversely associated with granular tau oligomers and neurofibrillary tangles in AD [37] and in a mutant tau model [5] (Figure 5). In addition to facilitating the removal of aggregates by chaperone-mediated autophagy (CMA), HSPs are known to prevent caspase activation, for which substrates include tau, APP, and HTT [59].

Parkinson's Disease. Parkinson's disease (PD) is characterized by gradual debilitation due to selective degeneration of dopaminergic neurons in the substantia nigra pars compacta $(\mathrm{SNpc})$ with a subsequent decline in dopamine (DA) in the nigrostriatal pathway [60-65]. Most PD cases are sporadic, and in rare cases it may be inherited. The common symptomatic feature of PD is bradykinesia, tremor, rigidity abnormalities in gait, and posture. The hallmark pathology of PD is accumulation of $\alpha$-synuclein, the main component of Lewy bodies in midbrain dopaminergic neurons [60-65]. Examination of Lewy bodies revealed the presence of not only $\alpha$-synuclein, but a variety of other proteins including, neurofilaments, ubiquitinated proteins, and several HSPs (HSP70 and HSP90) [66]. HSP70 is localized with $\alpha$-synuclein, dopamine transporter (DAT), parkin, proteasome subunits, and ubiquitin with ubiquitin carboxy-terminal hydrolase-L1 


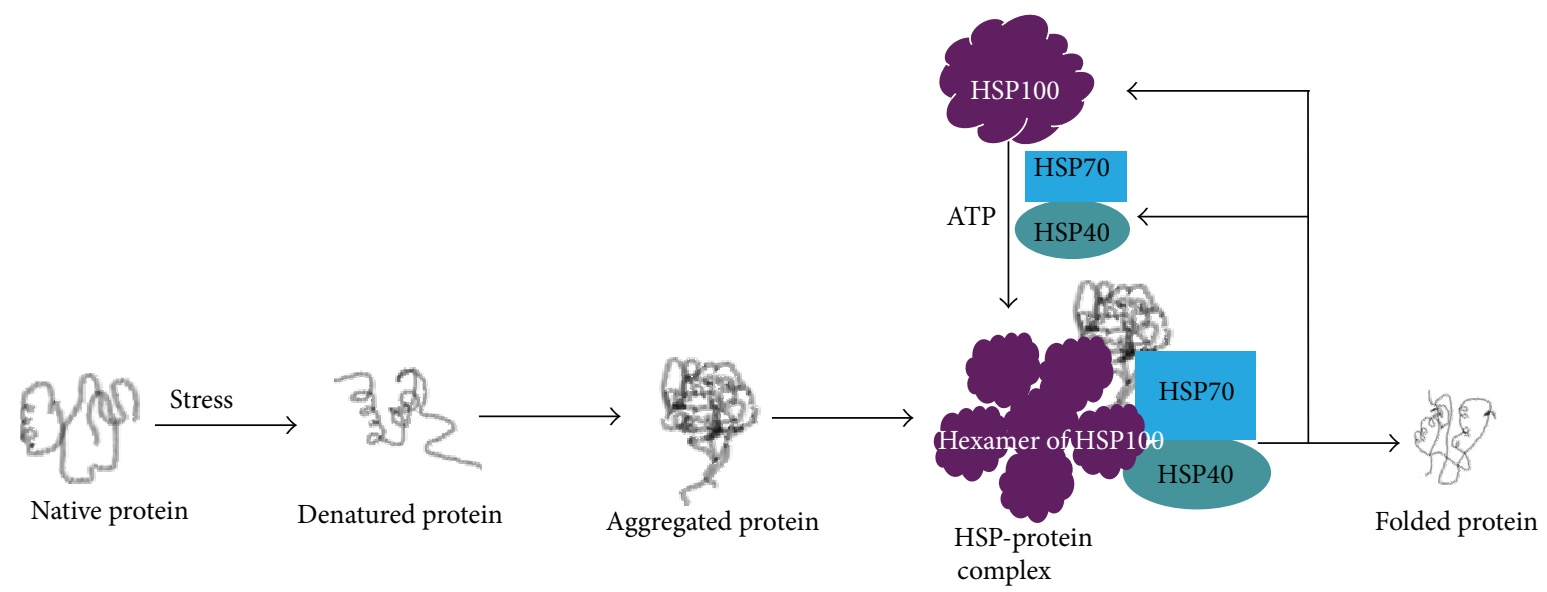

FIGURE 4: Role of HSP100 in protein folding and degradation. Along with HSP40 and HSP70, the hexameric form of HSP100 binds to the aggregated/misfolded protein to correct folding.

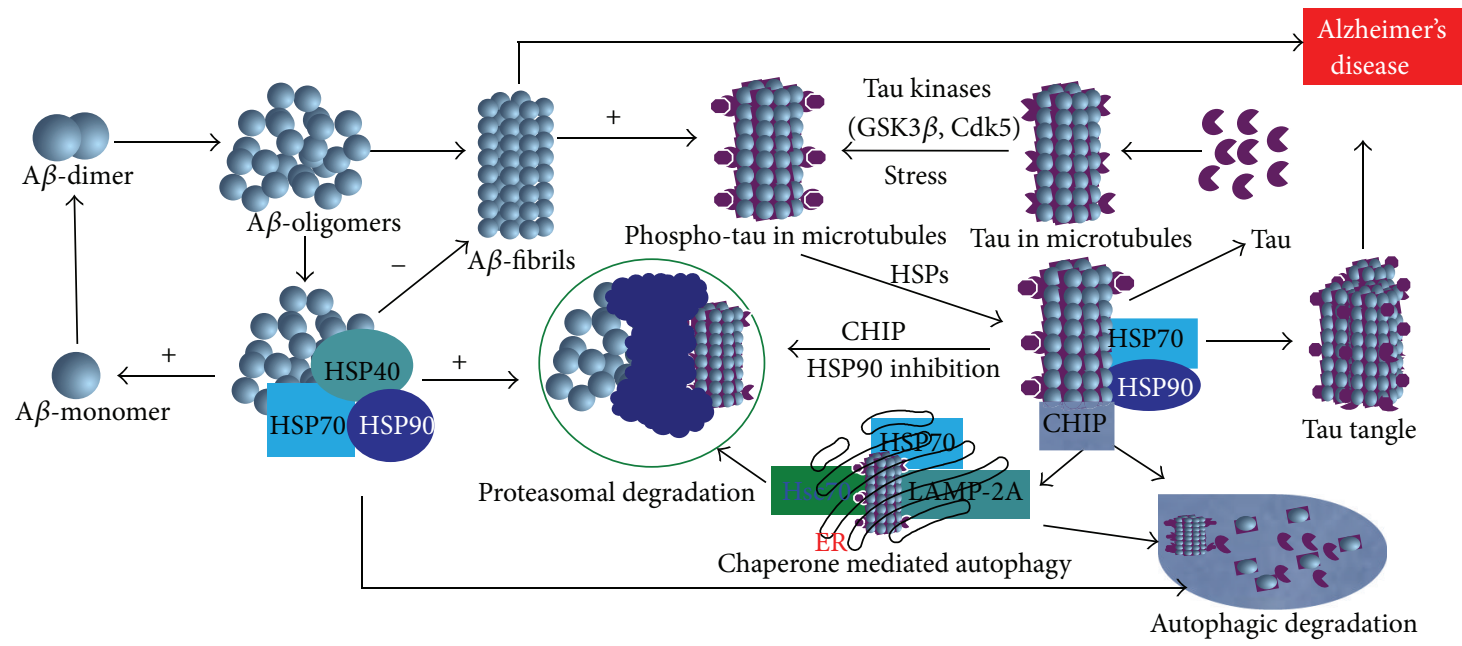

FIGURE 5: Role of molecular chaperones in Alzheimer's disease. HSP90, HSP70, and other client proteins are directly involved in degradation of $\mathrm{A} \beta$ oligomers and phosphorylated tau containing microtubule and help them to degrade either proteasome pathway or through autophagy pathway. Failure to dephosphorylate by HSPs leads to formation of tau tangle, a hallmark of AD.

(UCH-L1) [67]. HSP70 can prevent dopaminergic degeneration in PD due to its antiapoptotic activities $[68,69]$. Further, HSP70 can enhance parkin binding and ubiquitination of expanded polyglutamine protein in vitro and may help recruit misfolded proteins as substrates for parkin E3 ubiquitin ligase activity. Therefore, HSP70 can promote the activity of E3 ligase to degrade $\alpha$-synuclein (Figure 6).

Increasing HSPs may also have potential for therapeutic use in PD patients. Several studies suggest that increasing expression of HSP70 reduces alpha synuclein aggregation and toxicity [70-73]. Other HSPs like HSP40 or HSP27 may also reduce $\alpha$-synuclein aggregation [74]. Although one report showed that small molecule inhibitors of HSP90 reduce alpha synuclein oligomer formation and toxicity [75]. Uryu and coworkers demonstrated that expression of HSP90 is increased and associated with alpha-synuclein filaments in the brains of subjects with PD and in a transgenic mouse model of PD, implicating HSP90 in inclusion formation [76].
Huntington's Disease. Huntington disease (HD) is a progressive neurodegenerative disorder characterized by abnormal accumulation of huntingtin protein (HTT) due to several repetitions of glutamine (also called polyQ) [77, 78]. Misfolded HTT aggregation causes selective neuronal loss, primarily in the cortex and striatum, and also can lead to cognitive and motor impairments. The repetition of glutamine residue in HTT is critical for its toxicity: that is as the number of CAG repeats increases (CAG: gene code for glutamine), the HTT deposition and neurotoxicity are greater [79-81]. Interestingly, HSP70 is capable of preventing poly-glutamineinduced toxicity in $\mathrm{HD}$ models [82]. Increased levels of HSP40, HSP60, HSP70, and HSP100 have been shown to inhibit poly-glutamine-induced protein aggregation and thus attenuate disease progression [82-86]. Experimental data showed that HSP40 and HSP70 prevented intramolecular conformational changes in mutant HTT and attenuated the formation of spherical and annular HTT oligomers, 




Figure 6: Role of different HSPs in degradation of $\alpha$-synuclein in Parkinson's disease. HSP90, HSP70, HSP40, and HSP27 bind with polyubiquitinated $\alpha$-synuclein for proteasomal degradation to prevent dopaminergic neuronal loss in the substantia nigra.



FIGURE 7: Role of HSPs in prion degradation. Small HSPs such as HSP26 inhibit prion oligomer formation, and HSP42 prevents prionogenesis, whereas HSP70, HSP100, and HSP104 bind with large prion aggregates for degradation through the proteasomal or autophagy pathway.

thus promoting the accumulation of less toxic fibrillar and amorphous aggregates [36]. HSP70 has been shown to bind to the HTT exon containing a polyQ expansion primary mouse neurons in vitro and in yeast and colocalize to polyQ aggregates in vitro and in vivo; thus HSP70 might prevent aggregation by binding to a polyQ protein [36, 39]. HSP70 also inhibits oligomerization and fibril formation of polyQ and makes polyQ aggregates more soluble. Several studies reported that both HSP40 and HSP70 inhibit polyQ toxicity in cellular models as well as in vivo, and both can inhibit caspase- 3 and caspase- 9 activity as well as apoptosis-inducing factor (AIF) in HTT-transfected cells $[87,88]$. In HD, when the expression level of HSP27 is increased, it prevents polyglutamine-induced toxicity in neurons [89-91].

Prion Disease. Prion diseases are a family of rare progressive neurodegenerative disorders that affect both humans and animals. The "prions" are transmitted to tissue and induce abnormal folding of some specific proteins and transform them into pathogenic agents called prion proteins ( $\mathrm{PrP}$ ) [9296]. Prions can aggregate extracellularly within the CNS to form plaques known as prion plaques, which disrupt neuronal morphology. As a consequence several "holes" are observed in the tissue with resultant spongiform architecture due to vacuole formation in neurons. The central feature of prion diseases is the aggregation of pathologic prion proteins, such as $\mathrm{PrP}^{\mathrm{c}}$, an abnormal isoform of the cellular prion protein [92-96]. HSP70 binds to aggregated prion proteins and mediates their degradation through the proteasome pathway [36]. HSP70 plays an important role in the propagation of the $\mathrm{PrP}^{\mathrm{c}}$. Further, in yeast, overexpression of HSP100 leads to disassembly of large prion aggregates and generation of the small prion seeds for new rounds of prion propagation [93] (Figure 7).

Similarly, HSP104 can also inhibit the fibrillation and disassembly of prion peptide in vitro [97]. Duennwald et al. reported that yeast sHSPs such as HSP26 and HSP42 could attenuate prionogenesis. With the help of HSP70, HSP42 can prevent conformational rearrangements of prion oligomers, thus attenuating self-assembly, whereas HSP26 can bind to assembled prions oligomers and prevent their aggregation. Furthermore, HSP104, HSP70, and HSP40 destabilize prions and promote their disaggregation [98] (Figure 7).

\section{Natural Antidotes to Boost the HSP System}

Indeed, stimulation of HSPs has emerged as a potential strategy for the treatment of several neurodegenerative diseases $[12,99]$. Importantly many nontoxic, naturally occurring small molecules are now known to modulate function of or increase expression of HSPs. Increasing HSP expression in cells often elicits cytoprotective effects [41]. There are 
several compounds that can increase the heat shock response in cells including the potent HSPs activator, the antibiotic geldanamycin $[26,53,100]$. Compounds that boost the proteasomal pathway to eliminate the misfolded proteins or prevent the misfolding of protein also may have the potential to alleviate neurodegenerative diseases. Recently, naturally occurring traditional medicinal plant-derived, bioactive compounds like curcumin, celastrol, gambogic acid, and withaferin-A have been identified as HSPs activators [101, 102]. The adaptogens extracted from roots of Eleutherococcus senticosus, Schisandra chinensis berry, and Rhodiola rosea are also reported to increase HSP70 when tested in isolated human neuroglia cells [103]. Similarly, ethanolic leave extracts from Cichorium intybus and Jasminum sambac also induced HSP70 expression in $\mathrm{C} 2 \mathrm{C} 12$ myoblasts and rats tissue [104, 105]. All these research reports strongly suggest that natural bioactive phytochemicals have pivotal roles in increasing HSPs expression, which may prevent neurodegenerative diseases.

Polyphenol Curcumin Is a Natural Inducer of HSPs. Polyphenol curcumin is derived from the plant Curcumina longa. Curcumin has drawn special attention among all the polyphenol compounds because it has several beneficial effects in in vivo models of aging, ischemia and trauma [106-110], and animal models of several types of neurodegenerative diseases [31, 108-110]. It is a safe, FDA-approved, and naturally occurring amyloid binding polyphenolic molecule. Its pleiotropic antiamyloid properties suggest that it may have potential for the treatment of several neurodegenerative diseases [111]. Free (native) curcumin (unglucuronidated and unsulfated) readily crosses the blood brain barrier after oral administration and can act as an anti-inflammatory drug, antioxidant, and as an inhibitor of amyloid aggregation [54, 112]. In rodent models of $\mathrm{AD}$, administration of curcumin and related curcuminoids reduced plaque burden and protected against $\mathrm{A} \beta$-toxicity in vitro and in vivo, thereby improving cognitive function [112114]. In addition, our finding also suggested that treatment of CAG140 KI mice with 555 parts per million (ppm) of curcumin attenuated neuropathology and transcriptional deficits, including reduction levels of mutant HTT aggregates $[29,114]$.

Other polyphenols may have similar mechanisms of action, for example, (-) epigallocatechin gallate (EGCG) in green tea [115]. The fact that its binding to aggregates leads to creation of unstructured oligomeric species may be indicative of an alteration in the heat shock response. In fact similar to curcumin, in other cell models, EGCG has been shown that it binds to and inhibits HSP90 by blocking HSP70 association with HSP90 [116, 117]. However opposite to curcumin, it suppresses the induction of HSP70 [118]. Furthermore, our research demonstrated that curcumin administration decreases tau protein aggregation in human tau transgenic (hTauTg) mouse model [32]. Curcumin has also been shown to reduce soluble tau and increase HSPs in a human tau mouse model [26]. These results indicate that even after tangles are established, tau-dependent dysfunction of the synapses and behavior deficits can be corrected by curcumin treatment $[26,32]$.
Curcumin readily penetrates the brain where it is highly stable [110]. However, it is not stable in plasma and is excessively glucuronidated both in the intestine and by first pass metabolism, which limits penetration into the brain [110, 119122]. Recently, numerous approaches have been undertaken to improve the bioavailability of curcumin including the use of a glucuronidase inhibitor (e.g., piperine), liposomal curcumin (liposome/micelles), solid lipid curcumin nanoparticles [123], or a curcumin phospholipid complex [124]. Proper formulation is critical to achieve therapeutic levels of curcumin in humans, which show greater glucuronidation than rodents. Feeding mice 500 ppm in chow, a solid lipid nanoparticle containing curcumin (called Longvida, Verdure Sciences [123]), we achieved up to $5 \mu \mathrm{M}$ of curcumin in mouse brain tissue by two weeks (unpublished observations). Curcumin significantly decreased $A \beta$-plaque burden and improved memory of the mice model of $\mathrm{AD}[32,55,110]$. However, the molecular mechanism(s) behind curcumin's therapeutic effects remain unclear. One possibility is that it is targeting a common endogenous protein clearance pathway, such as the HSP system, that is, dysfunctional in neurodegenerative diseases. To test this hypothesis, we have examined the levels of HSPs and their client proteins (HSP90, HSP70, HSP70, HSP60, HSP40, CDC37, P23, FKBP51, etc.) in HD, tauopathies, and $\mathrm{AD}$ animal models of neurodegenerative diseases. We used the CAG140 (140-glutamine codon (CAG)) knockin mouse (CAG140KI) to model HD, which exhibits slowly progressing neurobehavioral impairments and accumulation of large HTT neuropil aggregates [114]. We used the hTau transgenic mouse, which overexpresses wild type human tau with a native promoter [125], and, to model AD, we used the triple transgenic rat (Swedish mutation in APP and mutation in presenilin-1 and presenilin-2) [126]. We observed that there were transgene-dependent reductions in HSPs and their clients, indicating molecular chaperones, are highly affected in all these amyloidogenic models. Interestingly, curcumin delivery was able to restore the levels of HSPs in these transgenic models (unpublished observations). We also looked at the levels of CDC37, P23, and FKBP51. CDC37 inhibited the HSP90 activity, whereas P23 and immunophilin FKBP51 activates it. The HSP90-binding immunophilin FKBP51 is a mitochondrial protein that translocates to the nucleus to protect cells against oxidative stress [127], and its level has been reported to be reduced in $\mathrm{AD}$ brain [128]. However, we found that CDC37, P23, and FKBP51 were significantly reduced in all three animal models, suggesting dysregulation of HSP90 cochaperones. In contrast mice fed curcumin showed no reduction in these client proteins.

In contrast, we observed that compared to wild type, there were significant increases in the levels of Fyn (unpublished observations), an important HSP90 client kinase [129], in all three amyloidogenic models, while curcumin reduced Fyn levels, independent from transgene. Dysregulation of Fyn is implicated in tau pathogenesis, because Fyn colocalizes with neurofibrillary tangle in AD brain [129], and it can phosphorylate tau at tyrosine 18 [130]. Further, since HSP90 inhibition selectively degrades many oncogenic client kinases including Src/Fyn [131], this finding further supports that Fyn suppression by curcumin may be via HSP90 inhibition. 
However, interestingly curcumin did not reduce another HSP90 relevant client protein Akt. The Akt can form complexes with HSP90 and HSP27, and active Akt is stabilized by interaction with HSP90. Recently, the interaction of HSP27 with Akt has been suggested to be involved in regulating apoptosis $[132,133]$. Hence, it is possible that HSPs modulate $\mathrm{A} \beta$, tau, and HTT toxicity through interactions with Akt. The transgene dependent loss of HSPs in these animal models may represent a failure to compensate for aggregate HTT, tau, or $\mathrm{A} \beta$ oligomers with aging and be relevant to the removal of those toxic aggregates as well as neuroprotection. Moreover, the early synaptic and axonal abnormalities in AD, PD, and HD may be reversed by HSPs [127]. Further, we have also investigated what the minimum dose of curcumin required to modulate HSPs is, and we found that even $0.01 \mu \mathrm{M}$ of curcumin was able to significantly increase HSP90 and HSP70 after $24 \mathrm{~h}$ of incubation in SH-SY5Y cells (unpublished observations). Thus, it is possible that by modulating HSP activity curcumin might inhibit or slow down amyloid formation and eventually reduces neuronal death in different neurodegenerative diseases.

\section{Conclusion}

In summary, protein misfolding and its progressive aggregation inside and outside of the cells are the common features of most of the neurodegenerative diseases. Molecular chaperones such as heat shock proteins play pivotal roles to guard against accumulation of damaged proteins in the cells that could trigger a pathophysiology. Thus harnessing the potential of HSPs is sought for ameliorating the pathology of several neurodegenerative diseases because of its protective role in protein folding and maturation and renaturation of misfolded proteins. Therefore, one of the important strategies to remove the toxic protein aggregates from cells is to boost the endogenous protein clearance pathways by activating the HSPs. Several phytochemicals including curcumin may ameliorate and circumvent deficits in molecular chaperones in amyloidogenic transgenic animal models. Therefore, restoration and upregulation of HSPs by curcumin is a promising therapeutic approach to relieve the adverse effect of accumulated misfolded proteins in several neurodegenerative diseases.

\section{Abbreviations}

$\begin{array}{ll}\text { HSP: } & \text { Heat shock protein } \\ \text { AD: } & \text { Alzheimer's disease } \\ \text { PD: } & \text { Parkinson's disease } \\ \text { MS: } & \text { Multiple sclerosis } \\ \text { HD: } & \text { Huntington's disease } \\ \text { HTT: } & \text { Huntingtin } \\ \text { A } \beta: & \text { Amyloid beta protein } \\ \text { APP: } & \text { Amyloid precursor protein } \\ \text { PFC: } & \text { Prefrontal cortex } \\ \text { UCHL1: } & \text { Ubiquitin carboxy-terminal } \\ & \text { hydroxylase-L1 } \\ \text { PrP }^{\text {sc }}: & \text { Prion protein scrapie form } \\ \text { PrP }^{c}: & \text { Prion protein cellular/common }\end{array}$

SOD: $\quad$ Superoxide dismutase

CNS: Central nervous system

HLA: Human leukocyte antigen

MW: Molecular weight

ATP: $\quad$ Adenosine triphosphate

ER: $\quad$ Endoplasmic reticulum

sHSPs: $\quad$ Small heat shock proteins

SBS: $\quad$ Substrate binding site

FKBP5: $\quad$ FK506 binding proteins

CYP: $\quad$ Cytochrome P450

TRP: $\quad$ Transient receptor potential

CMA: Chaperone mediated autophagy

LAMP-2A: Lysosome associated membrane protwin$2 \mathrm{~A}$

RNAi: Interference ribonucleic acid

HSC70: Heat shock cognate 70

NFT: Neurofibrillary tangle

SNpc: $\quad$ Substantia nigra parts compacta

DA: Dopamine

DAT: Dopamine transporter

AIF: $\quad$ Apoptotic inducing factor

FDA: $\quad$ Food and drug administration

CAG140KI: CAG140 knock in

Tg: Transgenic

$\mathrm{APP}_{\mathrm{Sw}}$ : Amyloid precursor protein Swedish

PS: Presenilin

htauTg: Human tau transgenic

ppm: $\quad$ Parts per million

CHIP: C-terminus of HSC70 interacting protein

CHO: Chinese hamster ovary.

\section{Conflict of Interests}

The authors declare that there is no conflict of interests regarding the publication of this paper.

\section{Acknowledgments}

This work was supported by Veterans Administration (Rehabilitation Grant RX000669 and Merit I01 BX001257), NIH RO1AG021975, NIH RC1AT006816, the Cure HD Initiative, and NIH Grant R01 (NS41574).

\section{References}

[1] D. J. Selkoe, "Cell biology of protein misfolding: the examples of Alzheimer's and Parkinson's diseases," Nature Cell Biology, vol. 6, no. 11, pp. 1054-1061, 2004.

[2] A. Cardinale, R. Chiesa, and M. Sierks, "Protein misfolding and neurodegenerative diseases," International Journal of Cell Biology, vol. 2014, Article ID 217371, 2 pages, 2014.

[3] J. P. Taylor, J. Hardy, and K. H. Fischbeck, "Toxic proteins in neurodegenerative disease," Science, vol. 296, no. 5575, pp. 1991$1995,2002$.

[4] A. Wyttenbach, J. Carmichael, J. Swartz et al., "Effects of heat shock, heat shock protein 40 (HDJ-2), and proteasome inhibition on protein aggregation in cellular models of Huntington's disease," Proceedings of the National Academy of Sciences of the United States of America, vol. 97, no. 6, pp. 2898-2903, 2000. 
[5] F. Dou, W. J. Netzer, K. Tanemura et al., "Chaperones increase association of tau protein with microtubules," Proceedings of the National Academy of Sciences of the United States of America, vol. 100, no. 2, pp. 721-726, 2003.

[6] A. M. Cataldo, D. J. Hamilton, J. L. Barnett, P. A. Paskevich, and R. A. Nixon, "Properties of the endosomal-lysosomal system in the human central nervous system: disturbances mark most neurons in populations at risk to degenerate in Alzheimer's disease," Journal of Neuroscience, vol. 16, no. 1, pp. 186-199, 1996.

[7] R. A. Nixon, "The role of autophagy in neurodegenerative disease," Nature Medicine, vol. 19, no. 8, pp. 983-997, 2013.

[8] D. G. Hay, K. Sathasivam, S. Tobaben et al., "Progressive decrease in chaperone protein levels in a mouse model of Huntington's disease and induction of stress proteins as a therapeutic approach," Human Molecular Genetics, vol. 13, no. 13, pp. 13891405, 2004.

[9] A. Klettner, "The induction of heat shock proteins as a potential strategy to treat neurogenerative disorders," Drug News and Perspectives, vol. 17, no. 5, pp. 299-306, 2004.

[10] V. Kakkar, M. Meister-Broekema, M. Minoia, S. Carra, and H. H. Kampinga, "Barcoding heat shock proteins to human diseases: looking beyond the heat shock response," DMM Disease Models and Mechanisms, vol. 7, no. 4, pp. 421-434, 2014.

[11] S. Takayama, J. C. Reed, and S. Homma, "Heat-shock proteins as regulators of apoptosis," Oncogene, vol. 22, no. 56, pp. 90419047, 2003.

[12] R. Bagatell and L. Whitesell, "Altered Hsp90 function in cancer: a unique therapeutic opportunity," Molecular Cancer Therapeutics, vol. 3, no. 8, pp. 1021-1030, 2004.

[13] R. J. Ellis, "Molecular chaperones: assisting assembly in addition to folding," Trends in Biochemical Sciences, vol. 31, no. 7, pp. 395401, 2006.

[14] R. J. Ellis, "Protein misassembly: macromolecular crowding and molecular chaperones," Advances in Experimental Medicine and Biology, vol. 594, pp. 1-13, 2007.

[15] R. J. Ellis and A. P. Minton, "Protein aggregation in crowded environments," Biological Chemistry, vol. 387, no. 5, pp. 485-497, 2006.

[16] K. Pauwels, I. Van Molle, J. Tommassen, and P. van Gelder, "Chaperoning anfinsen: the steric foldases," Molecular Microbiology, vol. 64, no. 4, pp. 917-922, 2007.

[17] J. H. Hoffmann, K. Linke, P. C. F. Graf, H. Lilie, and U. Jakob, "Identification of a redox-regulated chaperone network," EMBO Journal, vol. 23, no. 1, pp. 160-168, 2004.

[18] F. U. Hartl and M. Hayer-Hartl, "Molecular chaperones in the cytosol: from nascent chain to folded protein," Science, vol. 295, no. 5561, pp. 1852-1858, 2002.

[19] S. V. Slepenkov and S. N. Witt, "The unfolding story of the Escherichia coli Hsp70 DnaK: is DnaK a holdase or an unfoldase?” Molecular Microbiology, vol. 45, no. 5, pp. 1197-1206, 2002.

[20] M. Y. Sherman and A. L. Goldberg, "Cellular defenses against unfolded proteins: a cell biologist thinks about neurodegenerative diseases," Neuron, vol. 29, no. 1, pp. 15-32, 2001.

[21] K. Broersen, F. Rousseau, and J. Schymkowitz, "The culprit behind amyloid beta peptide related neurotoxicity in Alzheimer's disease: oligomer size or conformation?" Alzheimer's Research \& Therapy, vol. 2, no. 4, p. 12, 2010.

[22] D. Burdick, B. Soreghan, M. Kwon et al., "Assembly and aggregation properties of synthetic Alzheimer's A4/ $\beta$ amyloid peptide analogs," The Journal of Biological Chemistry, vol. 267, no. 1, pp. 546-554, 1992.
[23] G. Bitan, E. A. Fradinger, S. M. Spring, and D. B. Teplow, "Neurotoxic protein oligomers-what you see is not always what you get," Amyloid, vol. 12, no. 2, pp. 88-95, 2005.

[24] C. Haass and D. J. Selkoe, "Soluble protein oligomers in neurodegeneration: lessons from the Alzheimer's amyloid $\beta$ peptide," Nature Reviews Molecular Cell Biology, vol. 8, no. 2, pp. 101-112, 2007.

[25] R. Roychaudhuri, M. Yang, M. M. Hoshi, and D. B. Teplow, "Amyloid $\beta$-protein assembly and Alzheimer disease," Journal of Biological Chemistry, vol. 284, no. 8, pp. 4749-4753, 2009.

[26] C. Dickey, C. Kraft, U. Jinwal et al., "Aging analysis reveals slowed tau turnover and enhanced stress response in a mouse model of tauopathy," The American Journal of Pathology, vol. 174, no. 1, pp. 228-238, 2009.

[27] H. Shimura, D. Schwartz, S. P. Gygi, and K. S. Kosik, "CHIPHsc70 complex ubiquitinates phosphorylated tau and enhances cell survival," The Journal of Biological Chemistry, vol. 279, no. 6, pp. 4869-4876, 2004.

[28] A. Wyttenbach, "Role of heat shock proteins during polyglutamine neurodegeneration: mechanisms and hypothesis," Journal of Molecular Neuroscience, vol. 23, no. 1-2, pp. 69-95, 2004.

[29] B. Bercovich, I. Stancovski, A. Mayer et al., "Ubiquitin-dependent degradation of certain protein substrates in vitro requires the molecular chaperone Hsc70," The Journal of Biological Chemistry, vol. 272, no. 14, pp. 9002-9010, 1997.

[30] S. Kaushik and A. M. Cuervo, "Chaperone-mediated autophagy," Methods in Molecular Biology, vol. 445, pp. 227-244, 2008.

[31] U. Bandyopadhyay, S. Kaushik, L. Varticovski, and A. M. Cuervo, "The chaperone-mediated autophagy receptor organizes in dynamic protein complexes at the lysosomal membrane," Molecular and Cellular Biology, vol. 28, no. 18, pp. 57475763, 2008.

[32] Q.-L. Ma, X. Zuo, F. Yang et al., "Curcumin suppresses soluble tau dimers and corrects molecular chaperone, synaptic, and behavioral deficits in aged human tau transgenic mice," The Journal of Biological Chemistry, vol. 288, no. 6, pp. 4056-4065, 2013.

[33] M. V. Powers and P. Workman, "Inhibitors of the heat shock response: biology and pharmacology," FEBS Letters, vol. 581, no. 19, pp. 3758-3769, 2007.

[34] Y. Sun and T. H. MacRae, "The small heat shock proteins and their role in human disease," The FEBS Journal, vol. 272, no. 11, pp. 2613-2627, 2005.

[35] C. Sarto, P. A. Binz, and P. Mocarelli, "Heat shock proteins in human cancer," Electrophoresis, vol. 21, no. 6, pp. 1218-1226, 2000.

[36] N. R. Jana, M. Tanaka, G.-H. Wang, and N. Nukina, "Polyglutamine length-dependent interaction of Hsp40 and Hsp70 family chaperones with truncated N-terminal huntingtin: their role in suppression of aggregation and cellular toxicity," Human Molecular Genetics, vol. 9, no. 13, pp. 2009-2018, 2000.

[37] N. Sahara, S. Maeda, M. Murayama et al., "Assembly of two distinct dimers and higher-order oligomers from full-length tau," European Journal of Neuroscience, vol. 25, no. 10, pp. 30203029, 2007.

[38] D. W. Summers, P. M. Douglas, and D. M. Cyr, "Prion propagation by Hsp40 molecular chaperones." Prion, vol. 3, no. 2, pp. 59-64, 2009.

[39] P. J. Muchowski, G. Schaffar, A. Sittler, E. E. Wanker, M. K. Hayer-Hartl, and F. U. Hartl, "Hsp70 and Hsp40 chaperones can 
inhibit self-assembly of polyglutamine proteins into amyloidlike fibrils," Proceedings of the National Academy of Sciences of the United States of America, vol. 97, no. 14, pp. 7841-7846, 2000.

[40] W. Han and P. Christen, "cis-Effect of DnaJ on DnaK in ternary complexes with chimeric DnaK/DnaJ-binding peptides," FEBS Letters, vol. 563, no. 1-3, pp. 146-150, 2004.

[41] L. Tutar and Y. Tutar, "Heat shock proteins; an overview," Current Pharmaceutical Biotechnology, vol. 11, no. 2, pp. 216222, 2010.

[42] J. C. Ranford, A. R. Coates, and B. Henderson, "Chaperonins are cell-signalling proteins: the unfolding biology of molecular chaperones," Expert Reviews in Molecular Medicine, vol. 2, no. 8, pp. 1-17, 2000.

[43] H. Itoh, A. Komatsuda, H. Ohtani et al., "Mammalian HSP60 is quickly sorted into the mitochondria under conditions of dehydration," European Journal of Biochemistry, vol. 269, no. 23, pp. 5931-5938, 2002.

[44] C. Y. Fan, S. Lee, and D. M. Cyr, "Mechanisms for regulation of Hsp70 function by Hsp40," Cell Stress \& Chaperones, vol. 8, no. 4, pp. 309-316, 2003.

[45] K. Mapa, M. Sikor, V. Kudryavtsev et al., "The conformational dynamics of the mitochondrial Hsp70 chaperone," Molecular Cell, vol. 38, no. 1, pp. 89-100, 2010.

[46] F. Geraci, G. Turturici, and G. Sconzo, "Hsp70 and its molecular role in nervous system diseases," Biochemistry Research International, vol. 2011, Article ID 618127, 18 pages, 2011.

[47] S. K. Wandinger, K. Richter, and J. Buchner, "The Hsp90 chaperone machinery," The Journal of Biological Chemistry, vol. 283, no. 27, pp. 18473-18477, 2008.

[48] R. Zhao, M. Davey, Y.-C. Hsu et al., "Navigating the chaperone network: an integrative map of physical and genetic interactions mediated by the hsp90 chaperone," Cell, vol. 120, no. 5, pp. 715727, 2005.

[49] J. Trepel, M. Mollapour, G. Giaccone, and L. Neckers, “Targeting the dynamic HSP90 complex in cancer," Nature Reviews Cancer, vol. 10, no. 8, pp. 537-549, 2010.

[50] L. I. Gallo, M. Lagadari, G. Piwien-Pilipuk, and M. D. Galigniana, "The 90-kDa heat-shock protein (Hsp90)-binding immunophilin FKBP51 is a mitochondrial protein that translocates to the nucleus to protect cells against oxidative stress," The Journal of Biological Chemistry, vol. 286, no. 34, pp. $30152-$ 30160, 2011.

[51] E. C. Schirmer, J. R. Glover, M. A. Singer, and S. Lindquist, "HSP100/Clp proteins: a common mechanism explains diverse functions," Trends in Biochemical Sciences, vol. 21, no. 8, pp. 289296, 1996.

[52] S. Gottesman, C. Squires, E. Pichersky et al., "Conservation of the regulatory subunit for the Clp ATP-dependent protease in prokaryotes and eukaryotes," Proceedings of the National Academy of Sciences of the United States of America, vol. 87, no. 9, pp. 3513-3517, 1990.

[53] S. A. Frautschy, W. Hu, P. Kim et al., "Phenolic anti-inflammatory antioxidant reversal of $\mathrm{A} \beta$-induced cognitive deficits and neuropathology," Neurobiology of Aging, vol. 22, no. 6, pp. 993-1005, 2001.

[54] F. Yang, G. P. Lim, A. N. Begum et al., "Curcumin inhibits formation of amyloid $\beta$ oligomers and fibrils, binds plaques, and reduces amyloid in vivo," Journal of Biological Chemistry, vol. 280, no. 7, pp. 5892-5901, 2005.

[55] Y. Yang, R. S. Turner, and J. R. Gaut, "The chaperone BiP/GRP78 binds to amyloid precursor protein and decreases $A \beta 40$ and
A $\beta 42$ secretion," The Journal of Biological Chemistry, vol. 273, no. 40, pp. 25552-25555, 1998.

[56] M. Sarkar, J. Kuret, and G. Lee, "Two motifs within the tau microtubule-binding domain mediate its association with the hsc70 molecular chaperone," Journal of Neuroscience Research, vol. 86, no. 12, pp. 2763-2773, 2008.

[57] R. L. Matts, G. E. L. Brandt, Y. Lu et al., "A systematic protocol for the characterization of Hsp90 modulators," Bioorganic and Medicinal Chemistry, vol. 19, no. 1, pp. 684-692, 2011.

[58] L. Petrucelli, D. Dickson, K. Kehoe et al., "CHIP and Hsp70 regulate tau ubiquitination, degradation and aggregation," Human Molecular Genetics, vol. 13, no. 7, pp. 703-714, 2004.

[59] A. M. Cuervo and J. F. Dice, "Age-related decline in chaperonemediated autophagy," The Journal of Biological Chemistry, vol. 275, no. 40, pp. 31505-31513, 2000.

[60] T. Lebouvier, T. Chaumette, S. Paillusson et al., "The second brain and Parkinson's disease," The European Journal of Neuroscience, vol. 30, no. 5, pp. 735-741, 2009.

[61] L. M. de Lau and M. M. Breteler, "Epidemiology of Parkinson's disease," The Lancet Neurology, vol. 5, no. 6, pp. 525-535, 2006.

[62] A. J. Lees, J. Hardy, and T. Revesz, "Parkinson's disease," The Lancet, vol. 373, no. 9680, pp. 2055-2066, 2009.

[63] D. W. Dickson, "Parkinson's disease and parkinsonism: neuropathology," Cold Spring Harbor Perspectives in Medicine, vol. 2, no. 8, Article ID a009258, 2012.

[64] L. Stefanis, “ $\alpha$-synuclein in Parkinson's disease," Cold Spring Harbor Perspectives in Medicine, vol. 2, no. 2, Article ID a009399, 2012.

[65] H. A. Lashuel, C. R. Overk, A. Oueslati, and E. Masliah, "The many faces of $\alpha$-synuclein: from structure and toxicity to therapeutic target," Nature Reviews Neuroscience, vol. 14, no. 1, pp. 38-48, 2013.

[66] U. Dettmer, A. J. Newman, E. S. Luth, T. Bartels, and D. Selkoe, "In vivo cross-linking reveals principally oligomeric forms of $\alpha$-synuclein and $\beta$-synuclein in neurons and non-neural cells," Journal of Biological Chemistry, vol. 288, no. 9, pp. 6371-6385, 2013.

[67] P. J. McLean, H. Kawamata, and B. T. Hyman, “ $\alpha$-synucleinenhanced green fluorescent protein fusion proteins form proteasome sensitive inclusions in primary neurons," Neuroscience, vol. 104, no. 3, pp. 901-912, 2001.

[68] K. Santacruz, J. Lewis, T. Spires et al., "Medicine: tau suppression in a neurodegenerative mouse model improves memory function," Science, vol. 309, no. 5733, pp. 476-481, 2005.

[69] J. M. Shulman, P. L. de Jager, and M. B. Feany, "Parkinson's disease: genetics and pathogenesis," Annual Review of Pathology, vol. 6, pp. 193-222, 2011.

[70] P. K. Auluck, H. Y. E. Chan, J. Q. Trojanowski, V. M.-Y. Lee, and N. M. Bonini, "Chaperone suppression of $\alpha$-synuclein toxicity in a Drosophila model for Parkinson's disease," Science, vol. 295, no. 5556, pp. 865-868, 2002.

[71] C. Huang, H. Cheng, S. Hao et al., "Heat shock protein 70 inhibits $\alpha$-synuclein fibril formation via interactions with diverse intermediates," Journal of Molecular Biology, vol. 364, no. 3, pp. 323-336, 2006.

[72] M. M. Dedmon, J. Christodoulou, M. R. Wilson, and C. M. Dobson, "Heat shock protein 70 inhibits $\alpha$-synuclein fibril formation via preferential binding to prefibrillar species," The Journal of Biological Chemistry, vol. 280, no. 15, pp. 14733-14740, 2005. 
[73] Y. Zhou, G. Gu, D. R. Goodlett et al., "Analysis of $\alpha$-synucleinassociated proteins by quantitative proteomics," Journal of Biological Chemistry, vol. 279, no. 37, pp. 39155-39164, 2004.

[74] P. Thakur and B. Nehru, "Long-term heat shock proteins (HSPs) induction by carbenoxolone improves hallmark features of Parkinson's disease in a rotenone-based model," Neuropharmacology, vol. 79, pp. 190-200, 2014.

[75] P. Putcha, K. M. Danzer, L. R. Kranich et al., "Brain-permeable small-molecule inhibitors of Hsp90 prevent $\alpha$-synuclein oligomer formation and rescue $\alpha$-synuclein-induced toxicity," Journal of Pharmacology and Experimental Therapeutics, vol. 332, no. 3, pp. 849-857, 2010.

[76] K. Uryu, C. Richter-Landsberg, W. Welch et al., "Convergence of heat shock protein 90 with ubiquitin in filamentous $\alpha$ synuclein inclusions of $\alpha$-synucleinopathies," American Journal of Pathology, vol. 168, no. 3, pp. 947-961, 2006.

[77] S.-J. Lee, H.-S. Lim, E. Masliah, and H.-J. Lee, "Protein aggregate spreading in neurodegenerative diseases: problems and perspectives," Neuroscience Research, vol. 70, no. 4, pp. 339-348, 2011.

[78] B. S. Shastry, "Neurodegenerative disorders of protein aggregation," Neurochemistry International, vol. 43, no. 1, pp. 1-7, 2003.

[79] R. A. C. Roos, "Huntington's disease: a clinical review," Orphanet Journal of Rare Diseases, vol. 5, article 40, no. 1, 2010.

[80] J. F. Gusella and M. E. MacDonald, "Huntingtin: a single bait hooks many species," Current Opinion in Neurobiology, vol. 8, no. 3, pp. 425-430, 1998.

[81] S. Ramaswamy, K. M. Shannon, and J. H. Kordower, "Huntington's disease: pathological mechanisms and therapeutic strategies," Cell Transplantation, vol. 16, no. 3, pp. 301-312, 2007.

[82] C. Söti and P. Csermely, "Chaperones and aging: role in neurodegeneration and in other civilizational diseases," Neurochemistry International, vol. 41, no. 6, pp. 383-389, 2002.

[83] J. Carmichael, J. Chatellier, A. Woolfson, C. Milstein, A. R. Fersht, and D. C. Rubinsztein, "Bacterial and yeast chaperones reduce both aggregate formation and cell death in mammalian cell models of huntington's disease," Proceedings of the National Academy of Sciences of the United States of America, vol. 97, no. 17, pp. 9701-9705, 2000.

[84] C. J. Cummings, M. A. Mancini, B. Antalffy, D. B. DeFranco, H. T. Orr, and H. Y. Zoghbi, "Chaperone suppression of aggregation and altered subcellular proteasome localization imply protein misfolding in SCA1," Nature Genetics, vol. 19, no. 2, pp. 148-154, 1998.

[85] R. E. Hughes and J. M. Olson, "Therapeutic opportunities in polyglutamine disease," Nature Medicine, vol. 7, no. 4, pp. 419423, 2001.

[86] S. Krobitsch and S. Lindquist, "Aggregation of huntingtin in yeast varies with the length of the polyglutamine expansion and the expression of chaperone proteins," Proceedings of the National Academy of Sciences of the United States of America, vol. 97, no. 4, pp. 1589-1594, 2000.

[87] L. Ravagnan, S. Gurbuxani, S. A. Susin et al., "Heat-shock protein 70 antagonizes apoptosis-inducing factor," Nature Cell Biology, vol. 3, no. 9, pp. 839-843, 2001.

[88] S. Gurbuxani, E. Schmitt, C. Cande et al., "Heat shock protein 70 binding inhibits the nuclear import of apoptosis-inducing factor," Oncogene, vol. 22, no. 43, pp. 6669-6678, 2003.

[89] G.-R. Luo, S. Chen, and W.-D. Le, "Are heat shock proteins therapeutic target for Parkinson's disease?" International Journal of Biological Sciences, vol. 3, no. 1, pp. 20-26, 2007.
[90] T. F. Outeiro, J. Klucken, K. E. Strathearn et al., "Small heat shock proteins protect against $\alpha$-synuclein-induced toxicity and aggregation," Biochemical and Biophysical Research Communications, vol. 351, no. 3, pp. 631-638, 2006.

[91] M. M. Wilhelmus, W. C. Boelens, I. Otte-Höller, B. Kamps, R. M. W. de Waal, and M. M. Verbeek, "Small heat shock proteins inhibit amyloid- $\beta$ protein aggregation and cerebrovascular amyloid- $\beta$ protein toxicity," Brain Research, vol. 1089, no. 1, pp. 67-78, 2006.

[92] V. Daggett, "Structure-function aspects of prion proteins," Current Opinion in Biotechnology, vol. 9, no. 4, pp. 359-365, 1998.

[93] D. R. Taylor and N. M. Hooper, "The prion protein and lipid rafts," Molecular Membrane Biology, vol. 23, no. 1, pp. 89-99, 2006.

[94] F. Wang, F. Yang, Y. Hu et al., "Lipid interaction converts prion protein to a PrPSc-like proteinase k-resistant conformation under physiological conditions," Biochemistry, vol. 46, no. 23, pp. 7045-7053, 2007.

[95] P. Critchley, J. Kazlauskaite, R. Eason, and T. J. T. Pinheiro, "Binding of prion proteins to lipid membranes," Biochemical and Biophysical Research Communications, vol. 313, no. 3, pp. 559-567, 2004.

[96] J. F. Diedrich, R. I. Carp, and A. T. Haase, "Increased expression of heat shock protein, transferrin, and $\alpha 2$-microglobulin in astrocytes during scrapie," Microbial Pathogenesis, vol. 15, no. 1, pp. 1-6, 1993.

[97] Y.-H. Liu, Y.-L. Han, J. Song et al., "Heat shock protein 104 inhibited the fibrillization of prion peptide 106-126 and disassembled prion peptide 106-126 fibrils in vitro," The International Journal of Biochemistry and Cell Biology, vol. 43, no. 5, pp. 768-774, 2011.

[98] M. L. Duennwald, A. Echeverria, and J. Shorter, "Small heat shock proteins potentiate amyloid dissolution by protein disaggregases from yeast and humans," PLoS Biology, vol. 10, no. 6, Article ID e1001346, 2012.

[99] K. Kato, H. Ito, K. Kamei, and I. Iwamoto, "Stimulation of the stress-induced expression of stress proteins by curcumin in cultured cells and in rat tissues in vivo," Cell Stress \& Chaperones, vol. 3, no. 3, pp. 152-160, 1998.

[100] A. Opattova, P. Filipcik, M. Cente, and M. Novak, "Intracellular degradation of misfolded tau protein induced by geldanamycin is associated with activation of proteasome," Journal of Alzheimer's Disease, vol. 33, no. 2, pp. 339-348, 2013.

[101] Y.-Q. Zhang and K. D. Sarge, "Celastrol inhibits polyglutamine aggregation and toxicity though induction of the heat shock response," Journal of Molecular Medicine, vol. 85, no. 12, pp. 1421-1428, 2007.

[102] J. Davenport, J. R. Manjarrez, L. Peterson, B. Krumm, B. S. J. Blagg, and R. L. Matts, "Gambogic acid, a natural product inhibitor of Hsp90," Journal of Natural Products, vol. 74, no. 5, pp. 1085-1092, 2011.

[103] A. Asea, P. Kaur, A. Panossian, and K. G. Wikman, "Evaluation of molecular chaperons Hsp72 and neuropeptide $\mathrm{y}$ as characteristic markers of adaptogenic activity of plant extracts," Phytomedicine, vol. 20, no. 14, pp. 1323-1329, 2013.

[104] Y.-H. Lee, D.-H. Kim, Y. S. Kim, and T.-J. Kim, "Prevention of oxidative stress-induced apoptosis of $\mathrm{C} 2 \mathrm{C} 12$ myoblasts by a Cichorium intybus root extract," Bioscience, Biotechnology and Biochemistry, vol. 77, no. 2, pp. 375-377, 2013.

[105] A. S. Alrashdi, S. M. Salama, S. S. Alkiyumi et al., "Mechanisms of gastroprotective effects of ethanolic leaf extract of Jasminum sambac against $\mathrm{HCl} /$ Ethanol-induced gastric mucosal injury in 
rats," Evidence-based Complementary and Alternative Medicine, vol. 2012, Article ID 786426, 15 pages, 2012.

[106] F. A. Al-Omar, M. N. Nagi, M. M. Abdulgadir, K. S. Al Joni, and A. A. Al-Majed, "Immediate and delayed treatments with curcumin prevents forebrain ischemia-induced neuronal damage and oxidative insult in the rat hippocampus," Neurochemical Research, vol. 31, no. 5, pp. 611-618, 2006.

[107] K. Bala, B. C. Tripathy, and D. Sharma, "Neuroprotective and anti-ageing effects of curcumin in aged rat brain regions," Biogerontology, vol. 7, no. 2, pp. 81-89, 2006.

[108] S. Sharma, Y. Zhuang, Z. Ying, A. Wu, and F. Gomez-Pinilla, "Dietary curcumin supplementation counteracts reduction in levels of molecules involved in energy homeostasis after brain trauma," Neuroscience, vol. 161, no. 4, pp. 1037-1044, 2009.

[109] A. Wu, Z. Ying, and F. Gomez-Pinilla, "Dietary curcumin counteracts the outcome of traumatic brain injury on oxidative stress, synaptic plasticity, and cognition," Experimental Neurology, vol. 197, no. 2, pp. 309-317, 2006.

[110] A. N. Begum, M. R. Jones, G. P. Lim et al., "Curcumin structurefunction, bioavailability, and efficacy in models of neuroinflammation and Alzheimer's disease," Journal of Pharmacology and Experimental Therapeutics, vol. 326, no. 1, pp. 196-208, 2008.

[111] P. T. Grogan, K. D. Sleder, A. K. Samadi, H. Zhang, B. N. Timmermann, and M. S. Cohen, "Cytotoxicity of withaferin A in glioblastomas involves induction of an oxidative stressmediated heat shock response while altering Akt/mTOR and MAPK signaling pathways," Investigational New Drugs, vol. 31, no. 3, pp. 545-557, 2013.

[112] M. Garcia-Alloza, L. A. Borrelli, A. Rozkalne, B. T. Hyman, and B. J. Bacskai, "Curcumin labels amyloid pathology in vivo, disrupts existing plaques, and partially restores distorted neurites in an Alzheimer mouse model," Journal of Neurochemistry, vol. 102, no. 4, pp. 1095-1104, 2007.

[113] G. P. Lim, T. Chu, F. Yang, W. Beech, S. A. Frautschy, and G. M. Cole, "The curry spice curcumin reduces oxidative damage and amyloid pathology in an Alzheimer transgenic mouse," Journal of Neuroscience, vol. 21, no. 21, pp. 8370-8377, 2001.

[114] M. A. Hickey, C. Zhu, V. Medvedeva et al., "Improvement of neuropathology and transcriptional deficits in CAG 140 knockin mice supports a beneficial effect of dietary curcumin in Huntington's disease," Molecular Neurodegeneration, vol. 7, no. 1, article 12, 2012.

[115] D. E. Ehrnhoefer, J. Bieschke, A. Boeddrich et al., "EGCG redirects amyloidogenic polypeptides into unstructured, offpathway oligomers," Nature Structural and Molecular Biology, vol. 15, no. 6, pp. 558-566, 2008.

[116] C. M. Palermo, C. A. Westlake, and T. A. Gasiewicz, "Epigallocatechin gallate inhibits aryl hydrocarbon receptor gene transcription through an indirect mechanism involving binding to a $90 \mathrm{kDa}$ heat shock protein," Biochemistry, vol. 44, no. 13, pp. 5041-5052, 2005.

[117] Y. Li, T. Zhang, Y. Jiang, H.-F. Lee, S. J. Schwartz, and D. Sun, "(-)-Epigallocatechin-3-gallate inhibits Hsp90 function by impairing Hsp90 association with cochaperones in pancreatic cancer cell line mia paca-2," Molecular Pharmaceutics, vol. 6, no. 4, pp. 1152-1159, 2009.

[118] X.-Y. Tang and Y.-Q. Zhu, "Epigallocatechin-3-gallate suppressed the over-expression of HSP 70 and MDR1 induced by heat shock in SGC 7901," Journal of Chemotherapy, vol. 20, no. 3, pp. 355-360, 2008.

[119] L. Baum, C. W. K. Lam, S. K.-K. Cheung et al., "Six-month randomized, placebo-controlled, double-blind, pilot clinical trial of curcumin in patients with Alzheimer disease," Journal of Clinical Psychopharmacology, vol. 28, no. 1, pp. 110-113, 2008.

[120] G. Garcea, D. J. L. Jones, R. Singh et al., "Detection of curcumin and its metabolites in hepatic tissue and portal blood of patients following oral administration," British Journal of Cancer, vol. 90, no. 5, pp. 1011-1015, 2004.

[121] J. M. Ringman, S. A. Frautschy, G. M. Cole, D. L. Masterman, and J. L. Cummings, "A potential role of the curry spice curcumin in Alzheimer's disease," Current Alzheimer Research, vol. 2, no. 2, pp. 131-136, 2005.

[122] J. M. Ringman, S. A. Frautschy, E. Teng et al., "Oral curcumin for Alzheimer's disease: tolerability and efficacy in a 24-week randomized, double blind, placebo-controlled study," Alzheimer's Research and Therapy, vol. 4, article 43, no. 5, 2012.

[123] V. S. Gota, G. B. Maru, T. G. Soni, T. R. Gandhi, and M. G. Agarwal, "Safety and pharmacokinetics of a solid lipid curcumin particle formulation in osteosarcoma patients and healthy volunteers," Journal of Agricultural and Food Chemistry, vol. 58, no. 4, pp. 2095-2099, 2010.

[124] P. Anand, A. B. Kunnumakkara, R. A. Newman, and B. B. Aggarwal, "Bioavailability of curcumin: problems and promises," Molecular Pharmaceutics, vol. 4, no. 6, pp. 807-818, 2007.

[125] C. Andorfer, Y. Kress, M. Espinoza et al., "Hyperphosphorylation and aggregation of tau in mice expressing normal human tau isoforms," Journal of Neurochemistry, vol. 86, no. 3, pp. 582590, 2003.

[126] E. Teng, V. Kepe, S. A. Frautschy et al., "[F-18]FDDNP microPET imaging correlates with brain $\mathrm{A} \beta$ burden in a transgenic rat model of Alzheimer disease: effects of aging, in vivo blockade, and anti-A $\beta$ antibody treatment," Neurobiology of Disease, vol. 43, no. 3, pp. 565-575, 2011.

[127] J. R. Smith and P. Workman, "Targeting CDC37: an alternative, kinase-directed strategy for disruption of oncogenic chaperoning," Cell Cycle, vol. 8, no. 3, pp. 362-372, 2009.

[128] A. Citri, D. Harari, G. Shohat et al., "Hsp90 recognizes a common surface on client kinases," The Journal of Biological Chemistry, vol. 281, no. 20, pp. 14361-14369, 2006.

[129] G. J. Ho, M. Hashimoto, A. Adame et al., "Altered p59Fyn kinase expression accompanies disease progression in Alzheimer's disease: implications for its functional role," Neurobiology of Aging, vol. 26, no. 5, pp. 625-635, 2005.

[130] A. Maloney and P. Workman, "HSP90 as a new therapeutic target for cancer therapy: the story unfolds," Expert Opinion on Biological Therapy, vol. 2, no. 1, pp. 3-24, 2002.

[131] H. Konishi, H. Matsuzaki, M. Tanaka et al., "Activation of protein kinase B (Akt/RAC-protein kinase) by cellular stress and its association with heat shock protein Hsp27," FEBS Letters, vol. 410, no. 2-3, pp. 493-498, 1997.

[132] M. J. Rane, Y. Pan, S. Singh et al., "Heat shock protein 27 controls apoptosis by regulating Akt activation," The Journal of Biological Chemistry, vol. 278, no. 30, pp. 27828-27835, 2003.

[133] K. M. Mearow, M. E. Dodge, M. Rahimtula, and C. Yegappan, "Stress-mediated signaling in PC12 cells: the role of the small heat shock protein, Hsp27, and Akt in protecting cells from heat stress and nerve growth factor withdrawal," Journal of Neurochemistry, vol. 83, no. 2, pp. 452-462, 2002. 

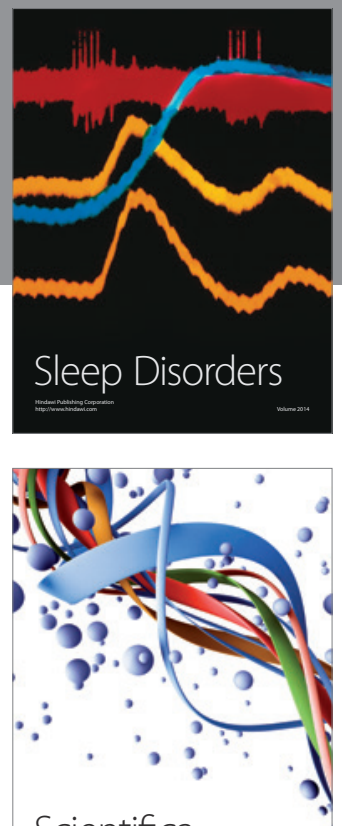

Scientifica
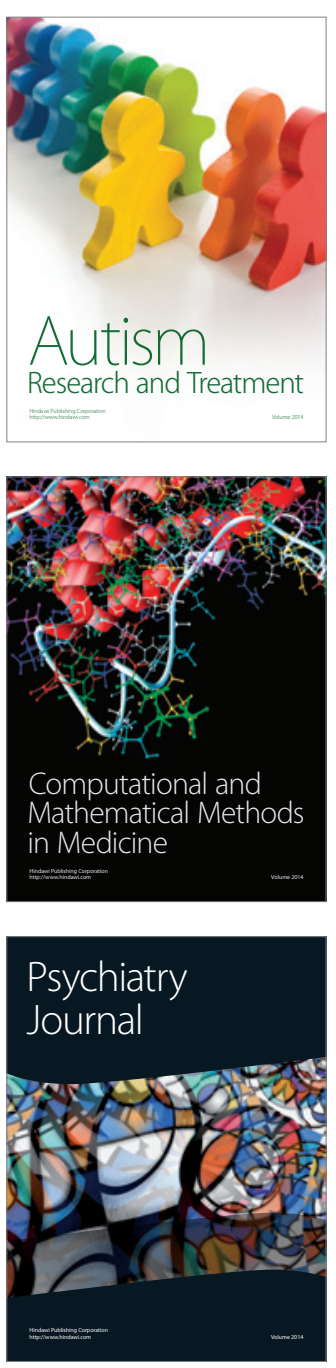
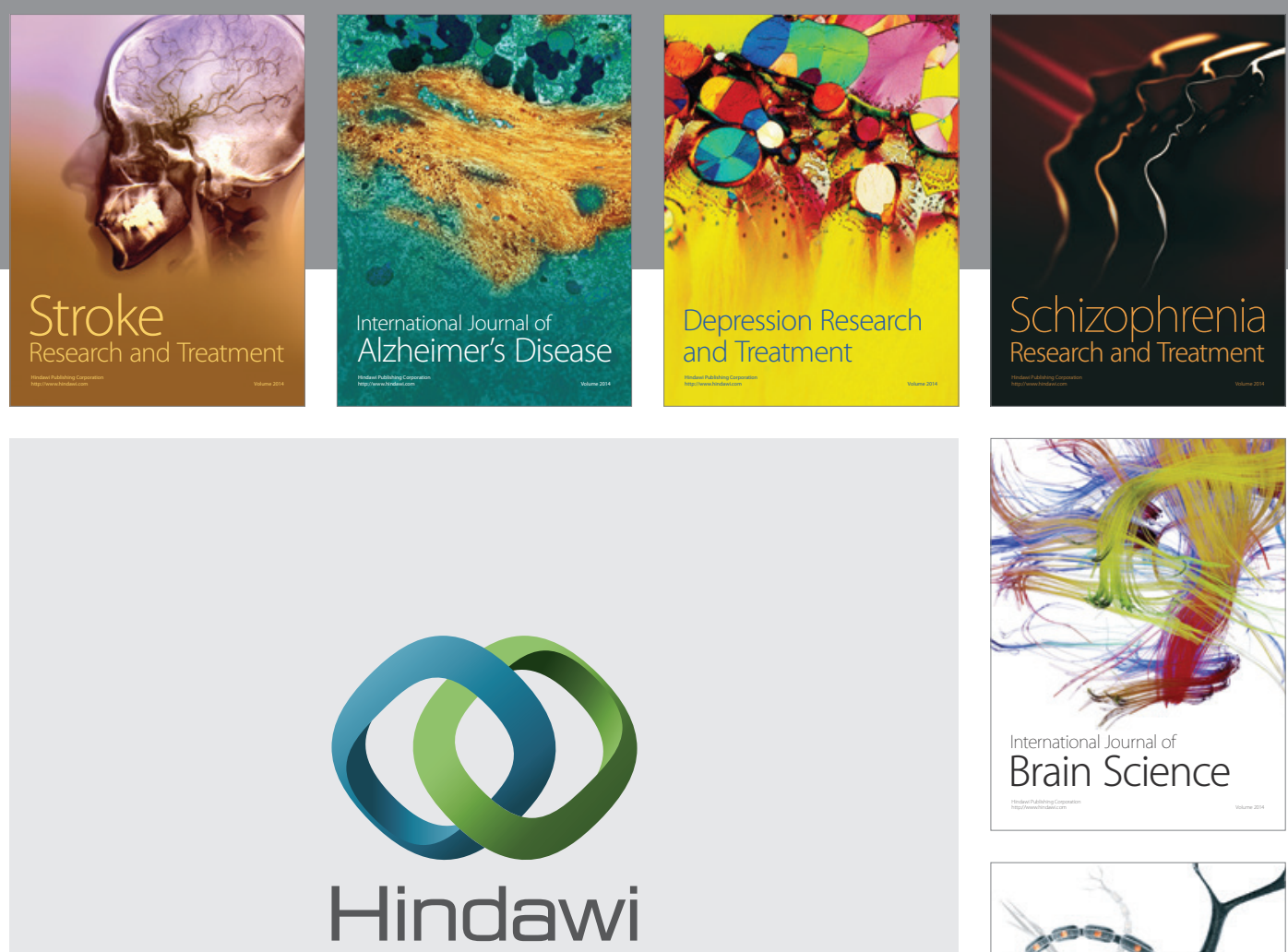

Submit your manuscripts at

http://www.hindawi.com
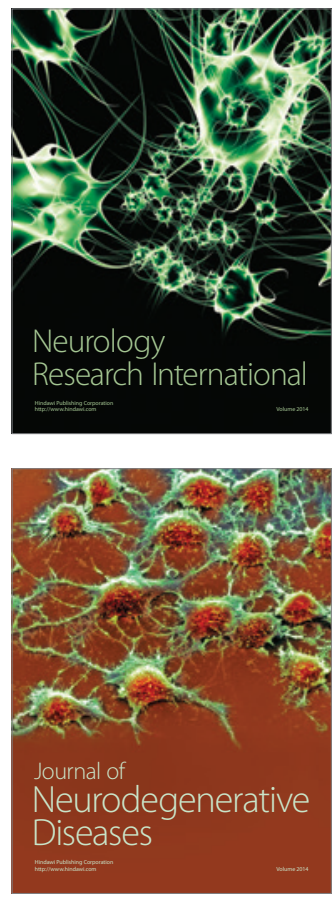



The Scientific World Journal
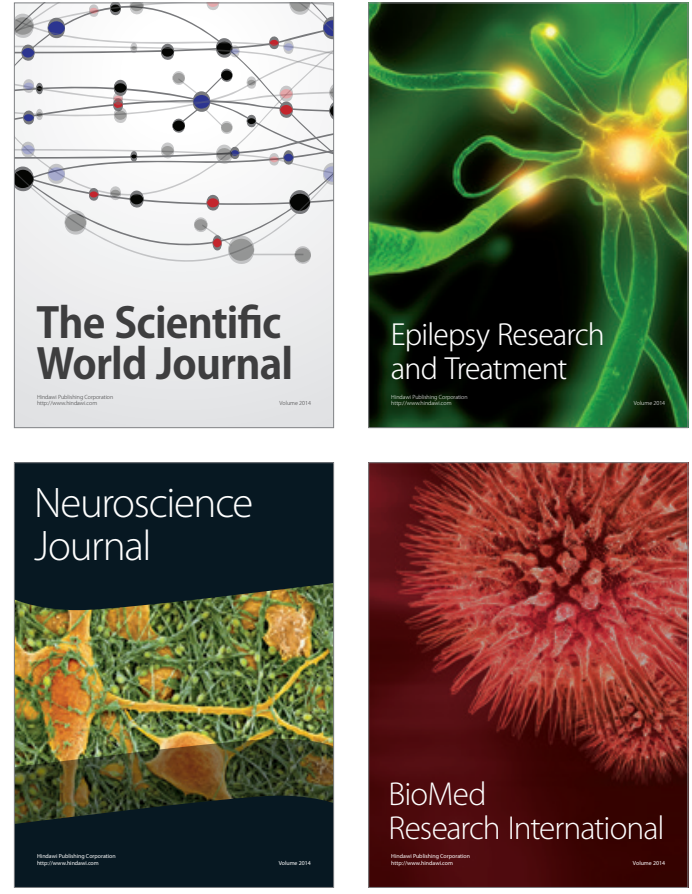

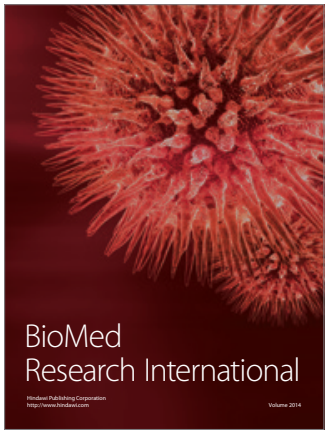

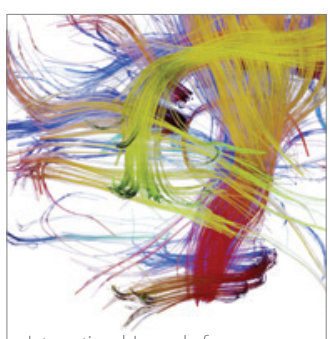

Brain Science

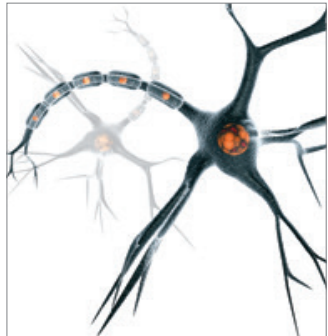

Neural Plasticity
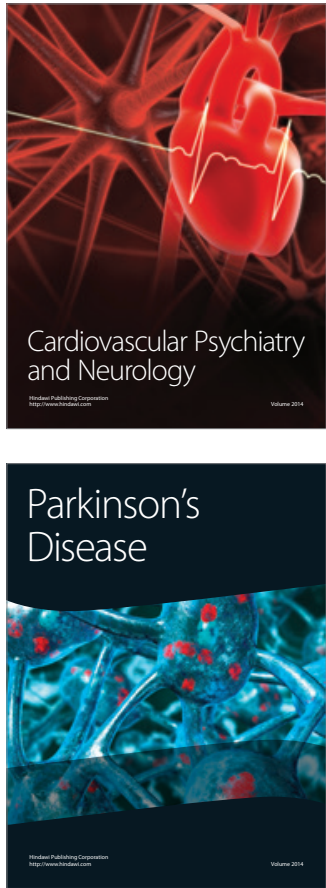